\title{
THE APPLICATION OF COMPUTER VISION FOR THE ESTIMATION OF SHRINKAGE AND DEFORMATION OF THIN MANGO SLICES DURING AIR DRYING PROCESS
}

\author{
Nguyen Duc Trung ${ }^{1}$, Pham Thanh Huong ${ }^{1}$, Nguyen Ngoc Hoang ${ }^{1}$, Dang Minh Hieu ${ }^{1}$, \\ Nguyen Nang Chat ${ }^{1}$, and Duong Quang $\mathrm{Ha}^{2}$ \\ ${ }^{1}$ Hanoi University of Science and Technology, Hanoi, Vietnam, Tel: +84.243.869.4242, \\ e-mail: trung.nguyenduc@ hust.edu.vn \\ ${ }^{2}$ University of Science and Technology of Hanoi, Vietnam Academy of Science and Technology, Hanoi, \\ Vietnam
}

Received Date: April 23, 2018; Revised Date: March 18, 2021; Acceptance Date: May 21, 2021

\begin{abstract}
Computer vision has been currently a new trend in developing new tools for automatic real-time quality control process in food drying. During drying process, the size and shape of mango slides are critically changed. These changes usually determine the sensorial value of products, as well as which drying conditions would be needed to obtain the highest quality of dried products. In this study, we report on the development of a computer vision tool, requiring a normal digital camera installed, to evaluate the changes in size and shape of mango slides during the drying process. The technique is expected to replace the observation with human eyes to evaluate the changes of food products during the drying process, which might not be able to provide reliable and consistent judgements all the time. Image of drying mango slide is taken by a digital camera, then the feature extraction is implemented. The area of mango slice is determined by the area ratio via the pixel number counting and the comparison to an original sample with predefined reference size. The shrinkage deformation is evaluated by elliptical fitting to develop the automated utility. The utility is built on MATLAB platform. The variations in size and shape of the mango slices during a convective drying process with different processing conditions are examined and acquired by the built software which achieves real-time performance on the personal laptop.
\end{abstract}

Keywords: Convective drying, Deformation, Mango slices, Shrinkage

\section{Introduction}

Mango (Mangifera indica) is a drupe fruit with fleshy and juicy mesocarp that has been considered as one of the most consumed fresh food in the world among the other major tropical fruits such as pineapples, papayas, avocados, bananas and so forth [1]. The main disadvantage of fresh mango is that mango contains high moisture, so it has a relatively short shelf life, which limits its commercialization and exportation. For the purpose of preserving foods, drying technology is one of the best choices to remove moisture and significantly prolong the shelf life, which makes dried mango slices achieve higher economic value than the fresh ones. In drying technology, quality assurance plays a critical role in product development and process optimization because the drying process causes many undesirable effects that make reductions in the functionality of final products. In terms of food sensory analysis, dry foods should be able to keep the whole sensorial value of the fresh ones, such as flavor, aroma, color, structure, size, and shape. Hence, the numerous studies in drying process of mango focused on the effects of 
ascorbic acid, salt, lemon juice, and honey on drying kinetics and sensory characteristic of dried mango [2,3], drying temperature on some quality attributes of mango slices [4], ascorbic and citric acid pretreatment on the quality mango slices [5] in order to find the way of improving the sensorial value of dried mango with the reservation of the four criteria: flavor, aroma, color or structure.

Recent studies also pay attention to the quality of dried mango, which is influenced by drying parameters in many drying techniques such as solar dryer [6, 7], air drying [8], infra-red light [9], freeze and microwave drying techniques [10], vacuum oven dryer [11], combined hot air and microwave-vacuum drying [12], low-pressure superheated steam drying [13] to improve the sensorial value of dried mango with the many criteria including structure and size.

To evaluate the quality of dried mango slices, size and shape are the two key sensorial criteria which determine the ability of the products to be selected and receive purchase decision. Current technology with selected value set of processing and treatment conditions including air velocity, air temperature, the thickness of mango slice, drying time, power, etc. $[14,15,16,17,18]$ still needs to monitor the shrinkage and deformation of mango slices during drying process. It is very difficult to make a realtime estimation the shrinkage or deformation of the object in drying chamber during several hours of the drying process by human visual inspection. However, with the aid of computer vision system, the procedure of evaluation can be performed continually, and faster; which improves the unavoidable deviation of human interpretation and helps to intelligently control the system performance. In fact, this nondestructive, cost-effective technique is able to obtain automatically both shrinkage and deformation information of thin mango slices from the obtained images via a digital camera connected to a computer. Based on the evaluation of the morphology, texture and color of the images, the in-situ quality of drying process will be determined [19].

Data acquired periodically can be treated with statistical methods to evaluate the effects of processing conditions on the changes of mango slices, which turn into the most suitable set values for the drying process including air velocity, air temperature or slice thickness so as to preserve the best quality of the dried mango slides from the fresh ones.

The objective of this study is to develop a utility for the real-time evaluation of both shrinkage and deformation information of drying mango slices, as well as to serve as an automate, helpful and affordable tool in food processing technology. The estimation of the deformation value is much more difficult than the estimation of the shrinkage value due to the reason that the shape of drying mango slices changed continuously under processing, so that the variation of shape was paid more attention than the variation of size in this study.

Moreover, the shrinkage of foods during drying process was also mentioned in recent studies $[20,21,22,23,24]$. Upon the featured shape of tropical mango in the commercial market, we selected the conventional image processing techniques combined with the elliptical data fitting in order to achieve the real-time estimation of the shrinkage with good accuracy during drying process.

The tool created and proposed in this study also can be easily deduced to monitor the variations of size and shape during the drying processes for not only mango slides, but also for other different types of fruits that has oval or spherical shapes. 


\section{Methodology and Experimental Equipment}

\section{The Shrinkage Index of Dried Mango Slices: Definition and Estimation}

Mathematical modeling of food system can provide the more accurate view of the structural changes during processing [24]. The shrinkage of dried mango slices, which is parameterized by the shrinkage index $\left(\mathrm{K}_{\mathrm{sh}}\right)$, is defined simply by the ratio of the area of current dried mango slice $\left(A_{n}\right)$ to that of initial fresh one $\left(A_{0}\right)$ because of moisture reduction during dehydration. The expression of shrinkage index is shown in the Equation (2a). The value of shrinkage index of every material is substantially smaller than or equal to one due to the dehydration happened during the drying process. The area of each mango slice (AMS) is determined by the comparison with predefined reference size of the original sample (Aos) via the snapshot of a pretreated image which includes them both in the same frame as shown in Figure 1. More detail about the pretreatment process to define the boundary of mango slices in the image is shown in the next part which introduces a utility built with MATLAB.

$$
\begin{aligned}
& A_{M S}=A_{O S} \frac{N_{M S}}{N_{O S}} \\
& K_{s h}=\frac{A_{n}}{A_{0}} \\
& S K_{n}=\frac{A_{n}}{A_{n-1}} \\
& K_{s h}=\frac{A_{n}}{A_{0}}=\frac{A_{n}}{A_{n-1}} \times \frac{A_{n-1}}{A_{n-2}} \times \ldots \times \frac{A_{2}}{A_{1}} \times \frac{A_{1}}{A_{0}}=S K_{n} \times S K_{n-1} \times \ldots \times S K_{2} \times S K_{1}
\end{aligned}
$$

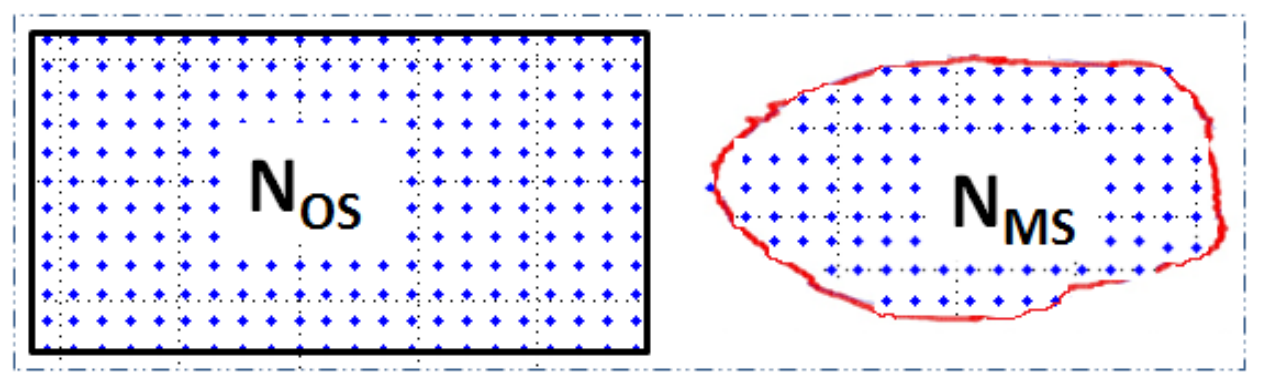

Figure 1. The original sample (OS) and the mango slice (MS) in the same frame

The area of mango slice is calculated indirectly by measuring the ratio of the pixel number of the mango slice (NMS) to the pixel number of an original sample (Nos) as shown in the Equation 1.

The simultaneous shrinkage index is defined as the ratio of the area of the dried mango slice $\left(A_{n}\right)$ to that of an initial fresh one $\left(A_{n-1}\right)$ as shown in the Equation $2 b$, so that the shrinkage index of the whole drying process $\left(\mathrm{K}_{\mathrm{sh}}\right)$ can be computed via the series of the simultaneous shrinkage index $\left(\mathrm{SK}_{1} \ldots \mathrm{SK}_{\mathrm{n}}\right)$ following the Equation $2 \mathrm{c}$. 


\section{The Deformation Index of Dried Mango Slices: Definition and Estimation}

The shapes of both fresh and dried mango slices from a downward view, in fact, do not show smoothly elliptical but can be approximated to elliptical shape as shown in Figure 2. The details of the fitting method and MATLAB programming for the utility is clarified in the next part. The deformation index $\left(\mathrm{K}_{\mathrm{df}}\right)$ is also estimated indirectly via the ratio of the shape index of the drying mango slice $\left(\mathrm{SI}_{n}\right)$ to that of the initial fresh one $\left(\mathrm{SI}_{0}\right)$ as illustrated in the Equation 4. The shape index is measured and computed by the ratio of the smaller one of the two axis of the fitted ellipse from the original boundary of considered mango slice ("a" and "a- $\Delta a$ " in the Figure 2) to the bigger one ("b" and "b- $\Delta b$ " in the Figure 2) as illustrated in the Equation $3 \mathrm{a}$ for SIn and in the Equation $3 \mathrm{~b}$ for SIo. In principle, the shape index is always smaller than one but the deformation index accepts every positive values.

$$
\begin{gathered}
S I_{0}=\frac{a}{b} \\
S I_{n}=\frac{a-\Delta a}{b-\Delta b} \\
K_{d f}=\frac{S I_{n}}{S I_{0}}=\frac{\frac{a-\Delta a}{b-\Delta b}}{\frac{a}{b}}=\frac{\frac{a-\Delta a}{b-\Delta b}}{\frac{a}{b}}=\frac{1-\frac{\Delta a}{a}}{1-\frac{\Delta b}{b}}
\end{gathered}
$$

It is difficult to keep the deformation index exactly at its ideal value which is one. The acceptable value for the deformation index should not be much bigger or smaller than the above-expected value as shown in Figure 2. The deformation index is also defined and estimated similarly, simultaneously with the shrinkage index to evaluate the variation of shape at each drying interval, however, as far as most technicians commonly will focus only on the deformation index.

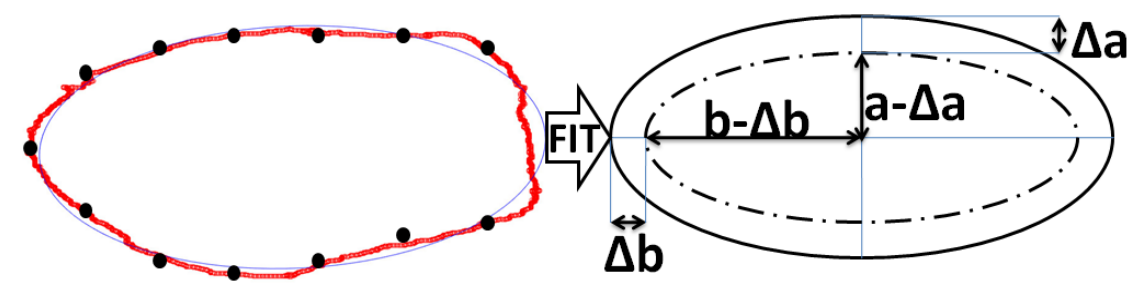

Figure 2. Elliptical fitting to estimate the shape variation of mango slice.

\section{Mango Sample Preparation}

Mangoes (Mangifera indica) were purchased in a local market (Hanoi, Vietnam). The fruits were selected based on their visual appearance with the same type and species. The mangoes used in this study were in the ripeness characterized by the yellowish color of $35 \%$ to $50 \%$ of their skin. They were taken from the same batch from the local supermarket and stored in the cooling chamber at $4^{\circ} \mathrm{C}$ until use. To do the experiment, the mango skin was peeled off, while the flesh was sliced and soaked in a solution containing $1 \%$ ascorbic acid before arranging on the drying tray. Three different thicknesses of the flesh, which were 3,5 , and $7 \mathrm{~mm}$, were tested subsequently which were named for $\mathrm{S} 1, \mathrm{~S} 2$, and $\mathrm{S} 3$, respectively. 


\section{Experimental Setup with Image Acquisition}

The air temperature at the inlet of drying chamber (4) of experimental convective drying machine is fully automatically controlled (1.a) in the range from $45^{\circ} \mathrm{C}$ to $110^{\circ} \mathrm{C}$ with $\pm 1^{\circ} \mathrm{C}$ of tolerance by the system with five contactors to switch between five independent electrical resistors (1.b). Each switch on resistor supplies $0.5 \mathrm{~kW}$ of thermal power to the drying air in the calorifier (3). The speed of a $250 \mathrm{~W}$ fan (2.b) is controlled manually by a potentiometer (2.a) to set the desired motor supply voltage from ACVR (Alternative Current Voltage Regulator) allowing the change of the dry air velocity from $1 \mathrm{~m} / \mathrm{s}$ to $3 \mathrm{~m} / \mathrm{s}$. The air flows outside through the exhaust pipe (9). The original sample whose size is about $20 \mathrm{~mm} \times 20 \mathrm{~mm}$ is arranged on tray (7) and placed in the drying chamber (4).

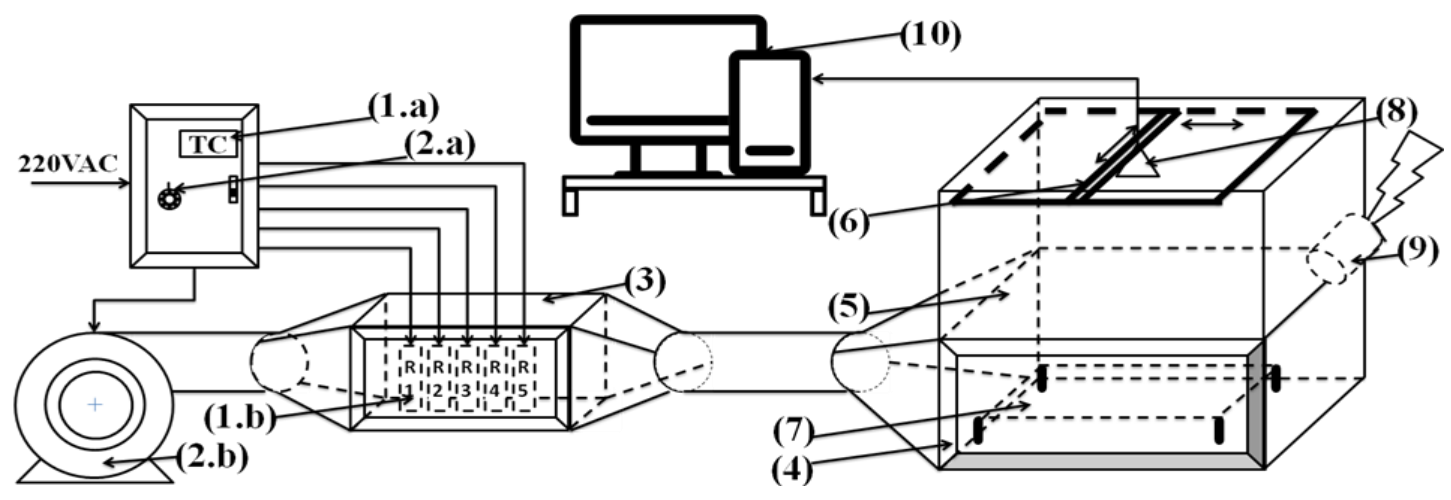

Figure 3. Convective drying equipment with image acquisition ability

A camera is connected via a DELL OPTIPLEX 3050 Computer with MATLAB Runtime environment on Windows 7 operating system (10) to capture images at each sampling time specified for each drying interval is isolated from hot air from the drying chamber by a thin transparent sheet (5). The camera can be moved to the desired position by a small drive system (6) with two independent motors allowing it to move in a $2 \mathrm{D}$ plane set at $700 \mathrm{~mm}$ above the surface of drying tray (7). The heights of drying objects will be always less than $700 \mathrm{~mm}$.

\section{Quality Control by Computer Vision System}

Computer vision system has recently played an important role in the quality inspection of food and agriculture products because the system employed automated, non-destructive and cost-effective techniques such as image analysis and processing to quantitatively characterize the complex size, shape, color and texture properties of foods [26]. The automated visual inspection that is basically composed of a light source, a camera for capturing the image at the output and a computational system for the extraction of characteristics and processing. MATLAB, a powerful numerical computing environment which provides a numerous set of standard algorithms for image processing and analysis [27], is used to characterize the mango slice. The MATLAB utility of image processing is shown in Figure 4.

\section{Image Processing}

Image processing is a method which performs some operations on an image to get the enhanced image and then the information needed to analyze can be retrieved. First, the images captured from the camera are imported. From a binary image, mango slices can be estimated by their perimeter, area. The process leading to the shape recognition is divided 
into the following steps: image preprocessing, e.g., background subtraction, noise filtering; feature extraction or shape description; eventually, comparison and estimation. The procedures of image size characterization are described in Figure 5.

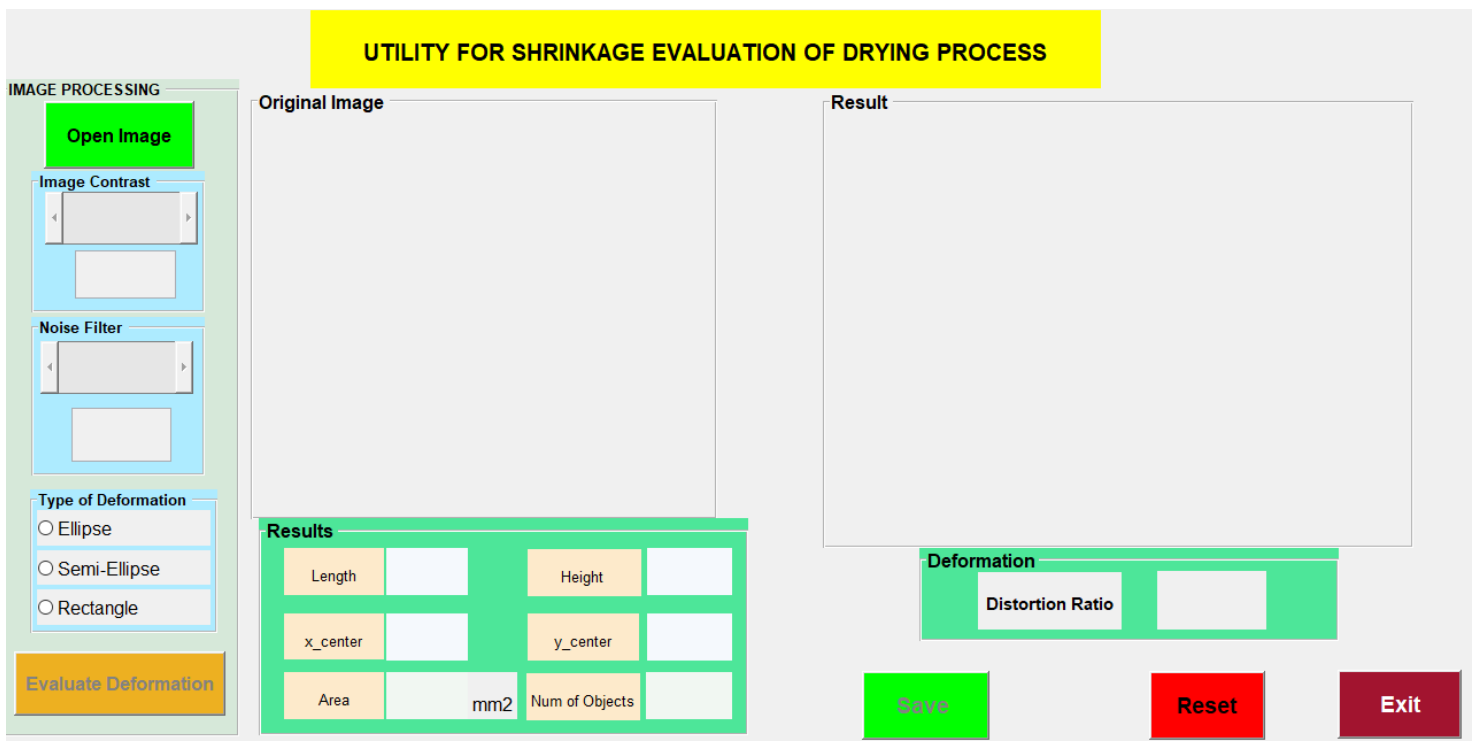

Figure 4. Utility for image processing and analysis of mango slice

\begin{tabular}{|c|c|c|c|c|}
\hline Image & Background & $\mathrm{Ga}$ & Thresholding & Image \\
\hline Acquisition & subtraction & noise filter & and eage & Analysis \\
\hline
\end{tabular}

Figure 5. Image processing for mango slices characterization

\section{Background Subtraction}

Background subtraction is the process of separating out foreground objects from the background in a sequence of frames. This technique is usually performed in the first processing stage of many computer vision systems to detect the object from the static camera in a particular scene. In fact, this technique approach minimizes many problems of segmenting objects when background scene textures change over time [28]. With the stable operation of the system and the purpose of real-time processing, we propose to apply the basic technique such as averaged background subtraction so as to reduce time-consuming and computational complexity. The background images are captured several times and the averaged background is deduced. Then, the image subtraction is performed to achieve the object location in the scene as shown in Figure 6.
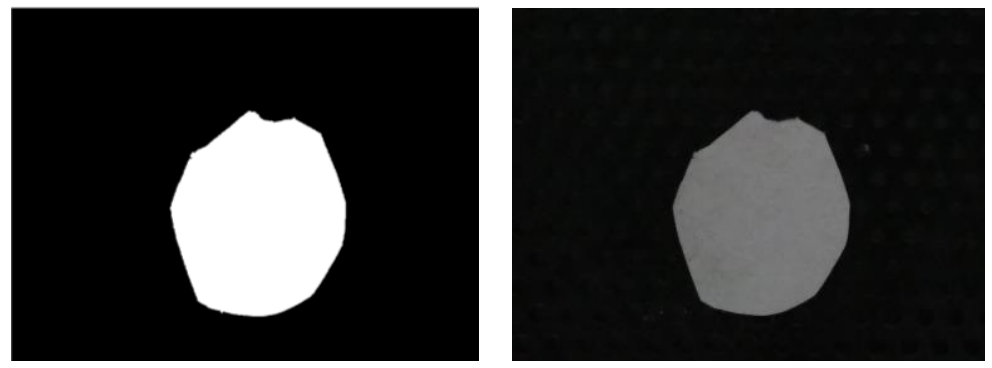

Figure 6 - The color (RGB) image of mango slice in drying room (left) and the gray image of mango slice after background subtraction (right) 


\section{Noise Filter}

Captured images are subjected to many kinds of noise, which degrades the quality of the subsequent image processing. Hence, noise filter is the next important step to remove the noise. In this system, noise reduction process is taken via image smoothing by $2 \mathrm{D}$ Gaussian filter.

\section{Edge Detection}

Segmentation process of the filtered image is continued with thresholding and edge detection. Thresholding and edge detection are the most commonly used techniques in image processing for pattern recognition when the object must be isolated from the background. For the sake of simplicity, single thresholding technique and Canny edge operator are implemented to detect the shape of mango slice. On the graphic user interface (GUI) of the utility, users can easily choose the threshold to achieve the best object location on the image. Figure 7 showed the mango slice shape after edge detection. The red line demonstrated the region of interest after processing.
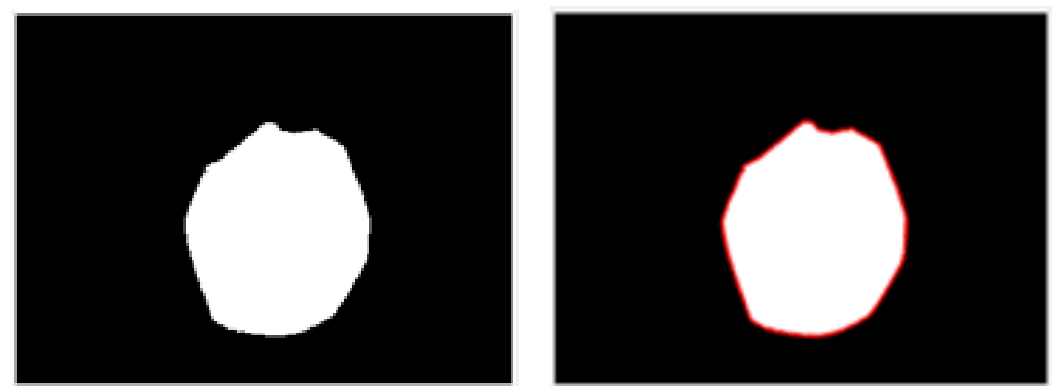

Figure 7 - The image of the object after noise filter (left) and the implementation of edge detection using MATLAB (right).

\section{Image Analysis}

The shape of mango slice containing meaningful information after drying is extracted. To characterize the mango slice after drying process, the shape of mango slice is fitted by the mathematical ellipse function by least-squares method [29] to detect the distortion ratio of the image. Based on this parameter, the shrinkage of mango slice after drying is deduced. Figure 8 shows the fitting image of mango shape by eclipse function on the utility.

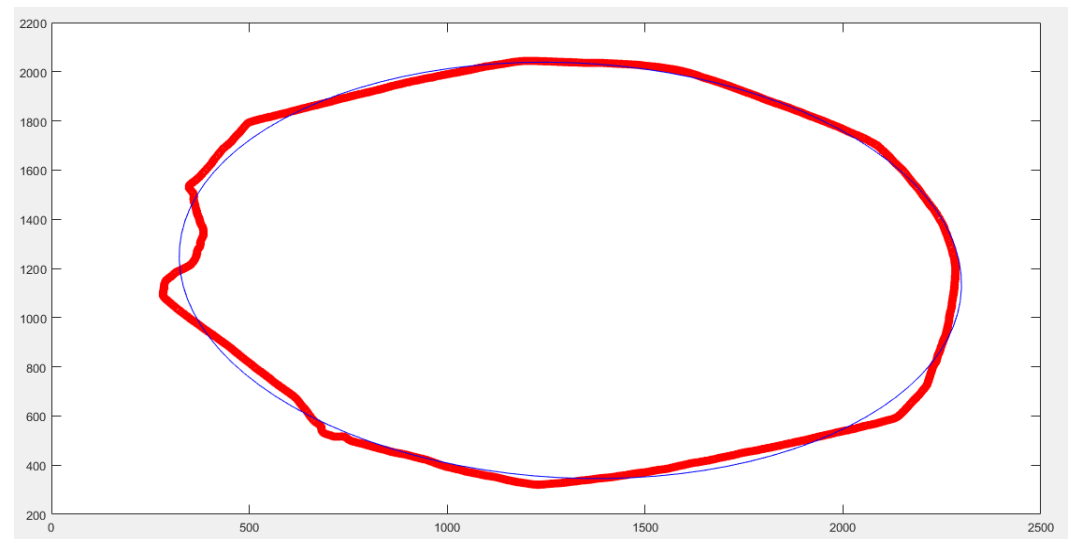

Figure 8 - The estimation of mango slice after drying by eclipse fitting, from which the shrinkage of mango slice during drying process is deduced (The red bold line is the shape of mango slice after edge detection, the blue thin line is the elliptical fitting curve). 


\section{Result and Discussion}

The utility testing results for the estimation of the shrinkage index $\left(K_{s h}\right)$ of mango slices S3 (thickness: $7 \mathrm{~mm}$ ) and the deformation index $\left(K_{d f}\right)$ of mango slices samples S1 (thickness: 3 $\mathrm{mm}$ ) and $\mathrm{S} 2$ (thickness: $5 \mathrm{~mm}$ ) during the drying process at different processing conditions: drying temperature $\left(\mathrm{T} 1: 60^{\circ} \mathrm{C} ; \mathrm{T} 2: 65^{\circ} \mathrm{C} ; \mathrm{T} 3: 70^{\circ} \mathrm{C} ; \mathrm{T} 4: 75^{\circ} \mathrm{C} ; \mathrm{T} 5: 80^{\circ} \mathrm{C}\right)$ and dry air velocity (V1: 1.0 m/s; V2: 1.25 m/s; V3: 1.5m/s) are shown in Figure 9 and Figure 10.

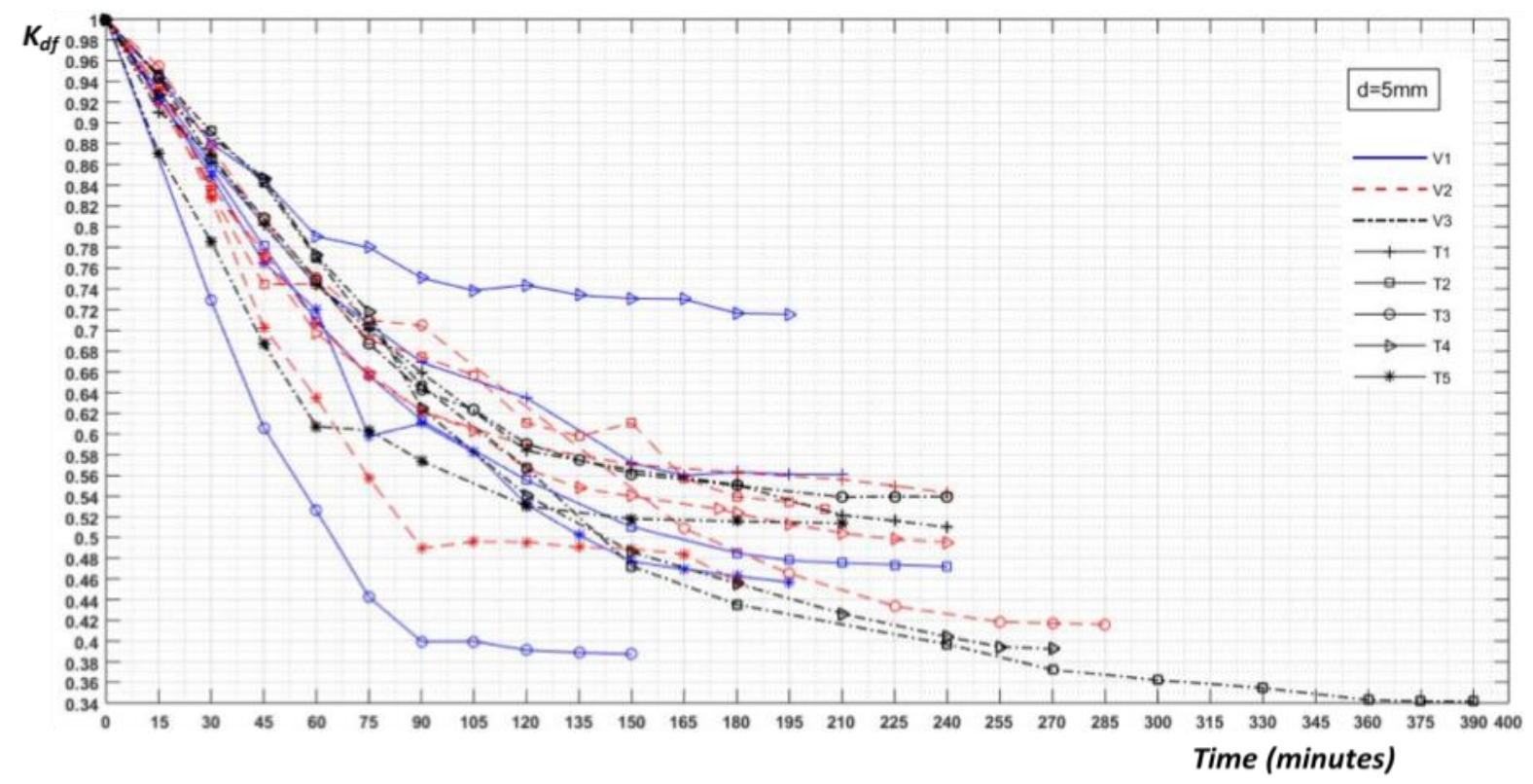

Figure 9. The shrinkage at different sampling time

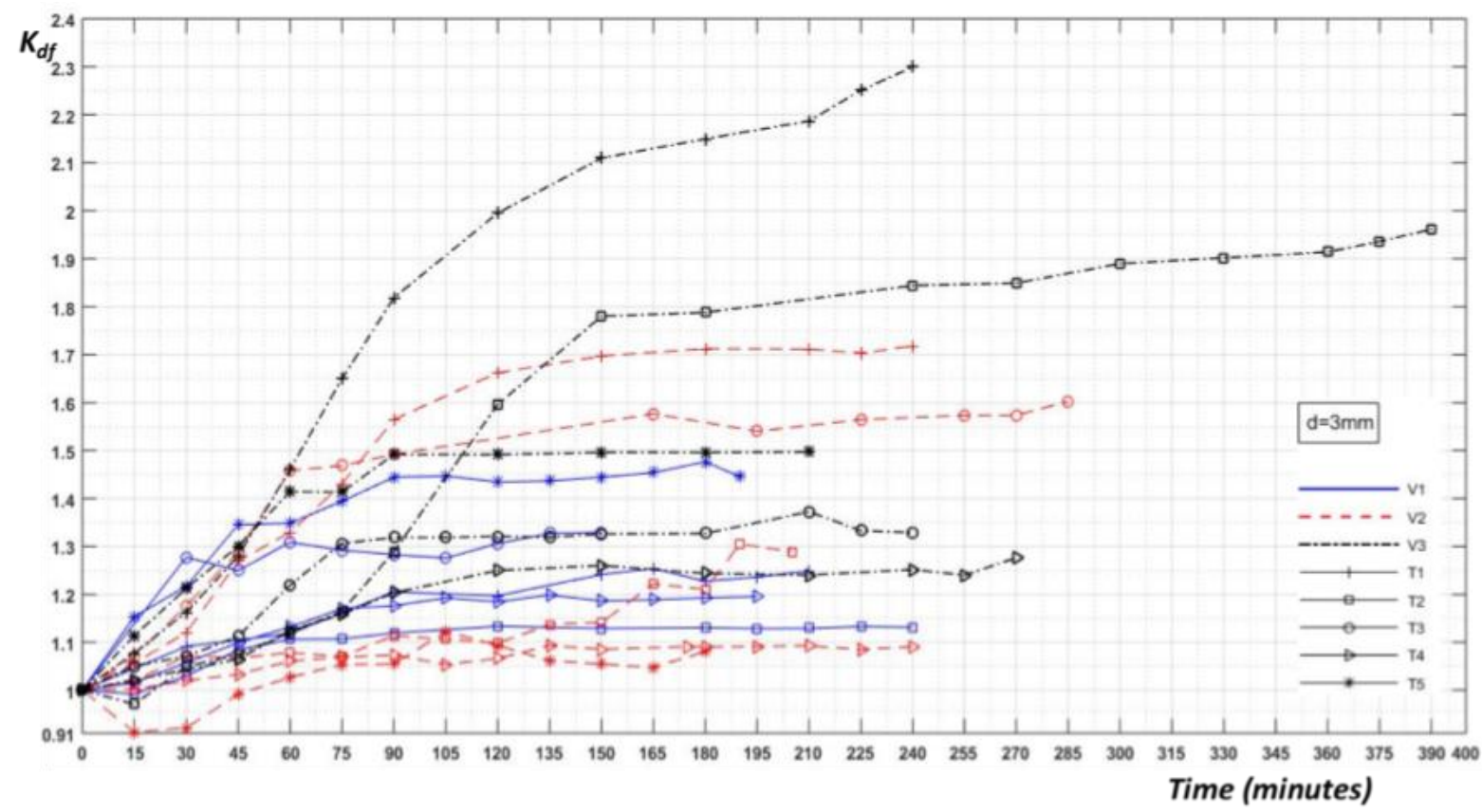

Figure 10. The deformation at different sampling time

The size and the shape also change very significantly depending on the thickness of samples so that the estimation of shrinkage and deformation is necessarily monitored to improve the sensorial value of dried products via the suitable selection of drying condition. 


\section{Conclusions}

We proposed a utility for the automated evaluation of the variations of size and shape of the mango slices during convective drying process by the method of area determination via pixel number comparison with reference size and elliptical fitting method. The thin slices of different kinds of fruits could be treated similarly to mango if their shapes from a downward view can be approximated to elliptical shapes. It is possible to apply the proposed utility of this study to evaluate the effects of processing factors on the shrinkage and deformation of sliced fruits in other studies.

The deformation of different kinds of dried foodstuffs with rectangularly or semielliptically downward-viewed shapes would be the next targets to be focused on in order to develop further our proposed utility into a packed complete software for 2D estimation of the shrinkage and deformation information. Another trend to be pursued would be a 3D estimation of the shrinkage and deformation information to apply not only to thin-sliced foodstuffs but also integrated foodstuffs.

\section{Acknowledgment}

This research is funded by the Hanoi University of Science and Technology (HUST) under project number T2017-PC-001.

\section{References}

[1] M. Siddiq, J.K. Brecht, and J.S. Sidhu, Handbook of Mango Fruit: Production, Postharvest Science, Processing Technology and Nutrition, John Wiley \& Sons, Oxford, United Kingdom, 2017.

[2] M.L. Gomez, and F.M. Lajolo, "Ascorbic acid metabolism in fruits: Activity of enzymes involved in synthesis and degradation during ripening in mango and guava," Journal of the Science of Food and Agriculture, Vol .88, No. 5, pp. 756-762, 2008. doi: $10.1002 /$ jsfa.3042.

[3] E.E. Abano, L.K. Sam-Amoah, J. Owusu, and F.N. Engmann, "Effects of ascorbic acid, salt, lemon juice, and honey on drying kinetics and sensory characteristic of dried mango," Croatian Journal of Food Science and Technology, Vol. 5, No.1, pp. 1-10, 2013 [Online].

Available: https://hrcak.srce.hr/index.php?show=clanak\&id_clanak_jezik=156342

[4] E.O.M. Akoy, "Effect of drying temperature on some quality attributes of mango slices," International Journal of Innovation and Scientific Research, Vol. 4, No. 2, pp. 91-99, 2014 [Online].

Available: http://www.ijisr.issr-journals.org/abstract.php?article=IJISR-14-130-02

[5] H. Desmorieuxa, C. Dialloa, and Y. Coulibaly, "Operation simulation of a convective and semi-industrial mango dryer," Journal of Food Engineering, Vol. 89, No. 2, pp. 119-127, 2008. doi: 10.1016/j.jfoodeng.2008.04.007.

[6] A.O. Dissa, J. Bathiebo, S. Kam, P.W. Savadogo, H. Desmorieux, and J. Koulidiati, "Modelling and experimental validation of thin layer indirect solar drying of mango slices," Renewable Energy, Vol. 34, No. 4, pp. 1000-1008, 2009. doi: 10.1016/j.renene.2008.08.006.

[7] C. Heilporn, B. Haut, A. Nonclerq, and L. Spreutels, "Design and operation of a mixed sun-gas solar dryer for mangoes in West Africa," Paper presented at $18^{\text {th }}$ International Drying Symposium, Xiamen, China, November 2012. 
[8] Z. Yan, M.J. Sousa-Gallagher, and F.A.R. Oliveira, "Shrinkage and porosity of banana, pineapple and mango slices during air-drying," Journal of Food Engineering, Vol. 84, No. 3, pp. 430-440, 2008. doi: 10.1016/j.jfoodeng.2007.06.004

[9] C.I. Ochoa-Martínez, P.T. Quintero, A.A. Ayala and M.J. Ortiz, "Drying characteristics of mango slices using the Refractance Window ${ }^{\mathrm{TM}}$ technique," Journal of Food Engineering, Vol. 109, No. 1, pp. 69-75, 2012. doi: 10.1016/j.jfoodeng.2011.09.032

[10] N. Izli, G. Izli, and O. Taskin, "Influence of different drying techniques on drying parameters of mango," Food Science and Technology, Vol. 37, No. 4, 2017. doi: $10.1590 / 1678-457 \times .28316$

[11] P.S. Kumar, and V.R. Sagar, "Drying kinetics and physico-chemical characteristics of osmo-dehydrated Mango, Guava and Aonla under different drying conditions," Journal of Food Science and Technology, Vol. 51, No. 8, pp. 1540-1546, 2014. doi: 10.1007/s13197-012-0658-3

[12] Y.Y. Pu, and D.W. Sun, "Combined hot-air and microwave-vacuum drying for improving drying uniformity of mango slices based on hyperspectral imaging visualisation of moisture content distribution," Bioengineering System, Vol. 156, pp. 108-119, 2017. doi: 10.1016/j.biosystemseng.2017.01.006

[13] R. Sehrawat, P.K. Nema, and B.P. Kaur, "Quality evaluation and drying characteristics of mango cubes dried using low-pressure superheated steam, vacuum and hot air drying methods," LWT - Food Science and Technology, Vol. 92, pp. 548555, 2018. doi: 10.1016/j.lwt.2018.03.012

[14] E.E. Abano, "Kinetics and quality of microwave-assisted drying of mango (mangifera indica)," International Journal of Food Science, Vol. 2016, 2016. doi: $10.1155 / 2016 / 2037029$

[15] D.G. Mercer, "A comparison of the kinetics of mango drying in open-air, solar, and forced-air dryers," African Journal of Food, Agriculture, Nutrition and Development, Vol. 12, No. 7, pp. 6835-6852, 2012 [Online].

Available: https://www.ajol.info/index.php/ajfand/article/view/84214

[16] L. Quintana-Zaragoza, G. Luna-Solano, M.A. Salgado-Cervantes, M. JimenezFernandez, G.R. Urrea-Garcia, and J. Villegas-Santiago, "Optimization and experimental validation of fluidized bed drying process of mango miniflakes," Revista Mexicana de Ingeniería Química, Vol. 16, No. 2, pp. 625-634, 2017 [Online].

Available: http://www.rmiq.org/ojs311/index.php/rmiq/issue/view/9

[17] J.V. Link, G. Tribuzi, and J.B. Laurindo, "Conductive multi-flash drying of mango slices: Vacuum pulse conditions on drying rate and product properties," Journal of Food Processing and Preservation, Vol. 42, No. 2, 2018. doi: 10.1111/jfpp.13440

[18] J. Villegas-Santiago, M. Calderon-Santoyo, A. Ragazzo-Sanchez, M.A. SalgadoCervantes, and G. Luna-Solano, "Fluidized bed and tray drying of thinly sliced mango (Mangifera - indica) pretreated with ascorbic and citric acid," International Journal of Food Science and Technology, Vol. 46, No. 6, pp. 1296-1302, 2011. doi: 10.1111/j.1365-2621.2011.02637.x

[19] A. Martynenko, "Chapter 2: Computer-aided control in drying," In Intelligent Control in Drying, A. Martynenko, and A. Bück, eds.: Taylor \& Francis, CRC Press, New York, United States, pp. 11-26, 2019.

[20] A.A. Kabiru, A.A. Joshua, and A.O. Raji, "Effect of slice thickness and temperature on the drying kinetics of mango (mangifera indica)," International Journal of Research and Reviews in Applied Sciences, Vol. 15, No. 1, pp. 41-50, 2013 [Online]. Available: www.arpapress.com/Volumes/Vol15Issue1/IJRRAS_15_1_06.pdf 
[21] A.O. Dissa, H. Desmorieux, and J. Koulidiati, "A convective thin layer drying model with shrinkage for kent mango slices," Advances in Chemical Engineering and Science, Vol. 6, No. 1, pp. 20-28, January 2016. doi: 10.4236/aces.2016.61002

[22] M.H. Nadian, S. Rafiee, S.S. Mohtasebi, S. Hosseinpour, and M. Khanali, "Determination of shrinkage and shape change of apple slices during drying," Paper presented at $7^{\text {th }}$ Asia-Pacific Drying Conference (ADC2011), Tianjin, China, September 2011.

[23] D. Witrowa-Rajchert, and M. Rząca, "Effect of drying method on the microstructure and physical properties of dried apples," Drying Technology, Vol. 27, No. 7-8, 2009. doi: 10.1080/07373930903017376

[24] M.A. Ebrahimi, S.S. Mohtasebi, Sh. Rafiee, and S. Hosseinpour, "Investigation of banana slices shrinkage using image processing technique," Australian Journal of Crop Science, Vol. 6, No. 5, pp. 938-945, 2012 [Online].

Available: http://www.cropj.com/may2012.html

[25] L. Mayor, and A.M. Sereno, "Modelling shrinkage during convective drying of food materials: A review," Journal of Food Engineering, Vol. 61, No. 3, pp. 373-386, 2004. doi: 10.1016/S0260-8774(03)00144-4

[26] D.W. Sun, ed., Computer Vision Technology for Food Quality Evaluation, $2^{\text {nd }}$ edition, Elsevier, London, United Kingdom, 2016.

[27] "Image Processing Toolbox, MathWorks" (n.d.) [Online]. Available: https://www.mathworks.com/ products/image.html [Accessed: April 2018]

[28] M. Piccardi, "Background subtraction techniques: a review," Paper presented at IEEE International Conference on System, Man and Cybernetics, Netherland, pp. 3099-3104, 2004. doi: 10.1109/ICSMC.2004.1400815

[29] K. Kanatani, Y. Sugaya and Y. Kanazawa, Ellipse Fitting for Computer Vision: Implementation and Applications, Morgan \& Claypool, 2016. doi: 10.2200/S00713ED1V01Y201603COV008 